\title{
EDITORIAL
}

\section{Meet the Experts ${ }^{\mathrm{TM}}$}

\section{R. Gunzburg ${ }^{1} \cdot$ Claudio Lamartina $^{2}$}

Received: 20 December 2017 / Accepted: 20 December 2017 / Published online: 30 January 2018

c) Springer-Verlag GmbH Germany, part of Springer Nature 2017

Over the last decade, and in line with many other scientific journals, the Editors of the European Spine Journal have placed an emphasis on education. The Open Operating Theatre educational film library is steadily growing and we are organizing workshops such as 'How to write and submit a paper' or 'How to be a good reviewer' during influential spine meetings such as SpineWeek (2016) and NSpine (2017). In 2015, we launched 'Meet the Experts' ${ }^{\mathrm{TM}}$ ', which we subsequently trademarked. The idea is as follows: we produce a special issue on a specific current topic and this is followed by an interactive symposium where the chapter authors present their papers and interact with the symposium registrants during 2 days of intensive ex-cathedra and handson workshops. The spinal osteotomy Meet the Experts ${ }^{\mathrm{TM}}$ was extremely well-received and led to a paper by Berjano et al. The effect of case-based discussion of topics with experts on learner's opinions: implications for spinal education and training [Eur Spine J (2017); 26(10):2660-2665], which we reprint here.

Our upcoming Meet the Experts ${ }^{\mathrm{TM}}$ 'Two Decades of Sagittal Balance' will be held in Madrid on March 16-17, 2018. Registration (limited to 130 participants to secure the interactivity between experts and participants) is possible via our website www.europeanspinejournal.org (news and events).

The Editors of the European Spine Journal would like to thank all those involved in this upcoming Meet the Experts $^{\mathrm{TM}}$ on 'Two decades of sagittal balance' and we look forward to more of these innovative activities.

\section{Compliance with ethical standards}

Conflict of interest None of the authors has any potential conflict of interest.
R. Gunzburg

robert@gunzburg.be

1 Cavell Spine Centre, Edith Cavell Clinic, Edith Cavell Street 32, 1180 Brussels, Belgium

2 II Spine Surgery Division, IRCSS Istituto Ortopedico Galeazzi, Via Riccardo Galeazzi, 4, 20161 Milan, Italy 